\title{
Severe familial intrahepatic cholestasis
}

\author{
M. ODIÈVRE, M. GAUTIER, M. HADCHOUEL, and D. ALAGILLE \\ From Clinique de pédiatrie de l'Unité d'Enseignement et de Recherche Médicale Paris-Sud; and Unité de Recherche \\ d'hépatologie infantile de l'Institut National de la Santé et de la Recherche Médicale, Hôpital Parrot, Bicêtre, France
}

Odièvre, M., Gautier, M., Hadchouel, M., and Alagille, D. (1973). Archives of Disease in Childhood, 48, 806. Severe familial intrahepatic cholestasis. Five cases of intrahepatic cholestasis are reported in 4 families in which 7 other children have had the same disease. Cholestasis, beginning before the age of one year, is notable for the absence of lipid retention, evolving by attacks brought on by intercurrent infections with gradual development of fibrosis and fatal cirrhosis before the age of 15. Extrahepatic and interlobular bile ducts are undamaged.

The disease is sometimes accompanied by biliary and pancreatic abnormalities, perhaps due to an abnormality in the biliary acid metabolism.

A particular form of intrahepatic cholestasis was first described in 1965 by Clayton et al. It is characterized by an alteration in the excretion of bilirubin, biliary acids, and bromsulphalein. It presents with the features of familial cholestatic cirrhosis, with a gradually fatal course. Since 1965, other cases have been published (Clayton et al., 1969; Gray and Saunders, 1966; Hirooka and Ono, 1968; Linarelli, Williams, and Phillips, 1972; Williams et al., 1972.)

The present work relates the clinical and biological study and the course of development of 5 new cases belonging to 4 different families.

\section{Case reports}

Case 1. A girl was born on 20 November 1964 weighing $2.4 \mathrm{~kg}$. At one year of age (during an attack of pharyngitis), she presented with jaundice, dark urine, acholic stools, pruritus, and hepatomegaly, lasting for 6 months and worsening during each intercurrent infection. The second attack took place at the age of 28 months during bronchitis; the liver then remained large and hard. The child was taken to hospital at the age of 4 because cholestasis persisted despite long-term steroid therapy.

The parents are first cousins; a brother and sister are in good health; one brother died at the age of 21 months from cirrhosis after a long history of cholestasis which began at the age of 3 weeks; her twin sister is Case 2.

On admission the child measured $93 \mathrm{~cm}(-2$ SD) and her weight was $12 \cdot 7 \mathrm{~kg}(-2 \mathrm{SD})$. Examination showed jaundice, dark urine, partially acholic stools, intense pruritus, and hepatosplenomegaly. Laboratory tests showed retention of bilirubin and bromsulphalein and

Received 8 March 1973. increase in alkaline phosphatase (Table I). Laparotomy, performed during regression of cholestasis, showed a large irregular liver and slender but permeable extrahepatic ducts containing thick black bile. The operation was completed by cholecystostomy and liver biopsy. Histological examination of the liver specimen showed moderately hypertrophic portal triads which sometimes became linked. These spaces contained a few round cells. The interlobular bile ducts were present and empty. Ductular formations were rare. Intralobular collagen was thickened, particularly in the periportal areas. Hepatocytes appeared normal, but were often grouped in pseudoacini.

After 5 weeks' external drainage, bilirubinaemia was $0.8 \mathrm{mg} / 100 \mathrm{ml}$, the bromsulphalein test was normal, and pruritus had disappeared. However, 11 days after the removal of the drain, pruritus reappeared, bromsulphalein excretion was again abnormal, bilirubin rose to $4 \cdot 6$ $\mathrm{mg} / 100 \mathrm{ml}$, and alkaline phosphatase to $261 \mathrm{IU}$. Treatment with cholestyramine $(8 \mathrm{~g} /$ day $)$ was ineffective, as was cholecystojejunostomy ( $\mathrm{Y}$ loop). Cholestyramine dosage was doubled to $16 \mathrm{~g}$ /day, also without effect. At the age of 5, the 'attack' suddenly ceased, but incompletely, the child still having moderate pruritus and a large liver. From 5 to 8 years of age there were several episodes of cholestasis associated with tonsillitis and lasting from 1 to 3 months. At the age of $6, x$-rays showed pancreatic calcifications. Needle liver biopsy showed a slight increase in the portal fibrosis with an annular tendency.

Case 2. The twin sister of Case 1 , weighing $2 \mathrm{~kg}$ at birth. The first attack of cholestasis took place at the age of 4 months with jaundice, acholic stools, and pruritus occurring over the course of several weeks. The second attack was at age one year, decreasing after 6 months, with fluctuations corresponding to seasonal infection. At age 2, after an attack of tonsillitis, a new attack lasting 
TABLE I

Principal biochemical data in 5 cases of severe familial intrahepatic cholestasis

\begin{tabular}{|c|c|c|c|c|c|}
\hline Case no. & 1 & 2 & 3 & 4 & 5 \\
\hline $\begin{array}{l}\text { Total bilirubin }(\mathrm{mg} / 100 \mathrm{ml}) \\
\text { Direct bilirubin }(\mathrm{mg} / 100 \mathrm{ml}) \\
\text { Total lipids (mg/100 ml) } \\
\text { Total cholesterol }(\mathrm{mg} / 100 \mathrm{ml}) \\
\text { Alkaline phosphatase }(\mathrm{IU}) \\
\text { Bromsulphalein (\% retention) } \\
15 \mathrm{~min} \\
45 \mathrm{~min} \\
\text { Prothrombin } \\
\text { Cholesterol esters (mg/100 ml) } \\
\text { SGPT } \\
\text { (Frankel units) } \\
\text { (mU/ml) } \\
\text { Flocculation tests } \\
\text { (Thymol, Kunkel-zinc, Hanger) }\end{array}$ & $\begin{array}{c}9 \cdot 4 \\
5 \cdot 4 \\
660 \\
190 \\
171 \\
66 \\
34 \\
\text { Normal } \\
145 \\
45\end{array}$ & $\begin{array}{c}16 \cdot 8 \\
10 \cdot 4 \\
700 \\
155 \\
195 \\
71 \\
48 \\
\text { Normal } \\
90 \\
80\end{array}$ & $\begin{array}{l}16 \cdot 6 \\
10 \cdot 5 \\
620 \\
190 \\
114 \\
69 \\
53 \\
\text { Normal } \\
165 \\
\\
128 \\
\text { Negative }\end{array}$ & $\begin{array}{l}3 \cdot 8 \\
2 \cdot 0 \\
600 \\
195 \\
264 \\
\\
25 \\
14 \\
\text { Normal } \\
110 \\
\\
180 \\
\text { Negative }\end{array}$ & $\begin{array}{c}10 \cdot 8 \\
3 \cdot 0 \\
500 \\
150 \\
203 \\
82 \\
56 \\
\text { Lowered } \\
70 \\
62\end{array}$ \\
\hline
\end{tabular}

3 weeks was followed by many others, remissions becoming less and less noticeable and the liver remaining large.

At the age of 4 she was taken to hospital, measuring 88.5 $\mathrm{cm}(-3 \mathrm{SD})$ and weighing $12 \cdot 6 \mathrm{~kg}(-2 \mathrm{SD})$. Jaundice and pruritus were severe and liver and spleen were enlarged. Biological tests were comparable with those of her sister (Table I).

Laparatomy showed a larger liver and lesions of chronic cholecystitis with 3 large calculi in the gallbladder; the head of the pancreas had the appearance of chronic pancreatitis. Peroperative cholangiography showed a slender but permeable bile duct. Histological examination of the liver biopsy showed highly hyper- trophic portal triads with many ductular formations, which made the definite identification of interlobular bile ducts difficult. There were some inflammatory cells. Periportal intralobular fibrosis was prominent. Hepatocytes were normal (Fig. 1).

When the cholecystostomy drain was removed, bilirubinaemia was $0.7 \mathrm{mg} / 100 \mathrm{ml}$, alkaline phosphatase $170 \mathrm{IU}$, bromsulphalein retention $34 \%$ at 15 minutes and $8 \%$ at 45 minutes. A relapse occurring 6 weeks later resisted cholestyramine (12 $\mathrm{g} /$ day) and lasted 2 months. Two other attacks took place at 5 years of age associated with pharyngitis, and one at $6 \frac{1}{2}$ years associated with bronchitis. The liver remained large and firm between the attacks; histological investigation of the liver

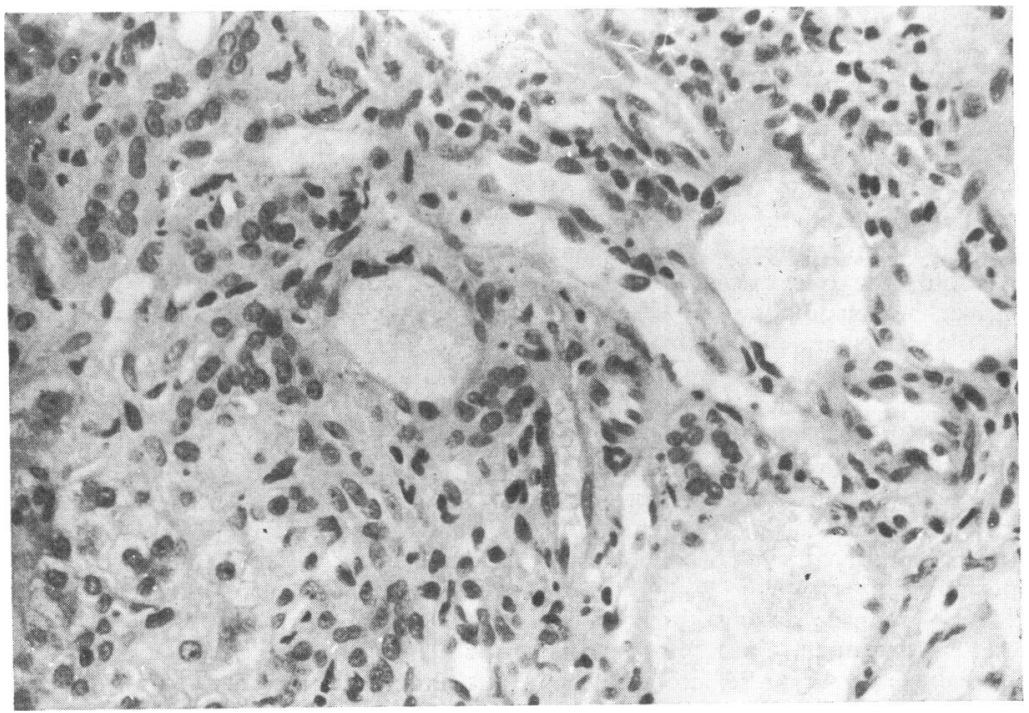

Fig. 1.-Case 2. Liver biopsy. Hypertrophic portal space. Interlobular bile duct clearly visible. Numerous neocanal formations. Some inflammatory cells. (Haematein eosin. $>370$. 


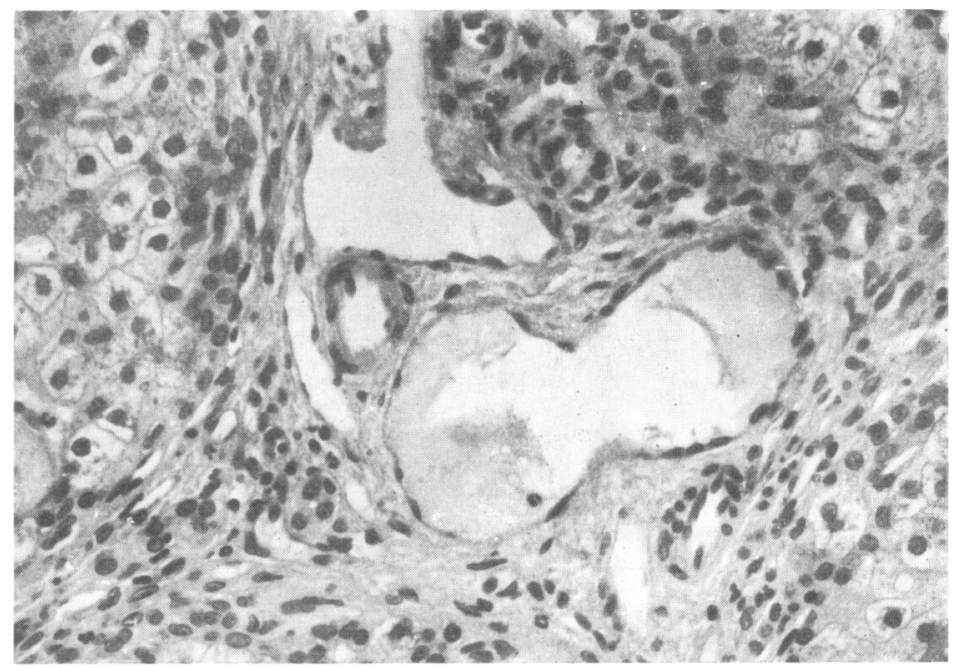

Frg. 2.-Case 3. Postmortem liver examination. Hypertrophic portal space. Interlobular bile duct is present. Some inflammatory cells. (Haematein eosin. $\times 315$.)

showed aggravated lesions. Ductular proliferation was evident and there were many inflammatory cells.

Case 3. A girl was born on 2 November 1966, weighing $3.4 \mathrm{~kg}$. Jaundice was noticed at 10 months, and was preceeded by considerable pruritus starting at 8 months. The parents are unrelated. A sister is healthy; another sister died at the age of $2 \frac{1}{2}$ years with liver cirrhosis and pruritus, and without atresia of intraor extrahepatic bile ducts.

At the age of 11 months she was taken to hospital measuring $75 \mathrm{~cm}(+1 \mathrm{SD})$ and weighing $8 \mathrm{~kg}$. Jaundice, dark-coloured urine, partially acholic stools, severe pruritus, and hepatosplenomegaly were noted. Biological tests showed retention of bilirubin and bromsulphalein; alkaline phosphatase was moderately increased (Table I). Laparotomy was performed showing the bile to be greenish and viscous in the gallbladder; washing with serum brought back a mucous plug and then the rest of the bile ducts were easily opacified. Peroperative cholangiography showed normal extrahepatic bile ducts and small-sized intrahepatic bile ducts. Histological examination of the liver biopsy specimen showed a distinct annular fibrosis, while portal triads were moderately thickened. Interlobular bile ducts were present. There were neither ductular formations nor inflammatory cells. In contrast, there was a well-marked intralobular fibrosis predominating in the centrolobular areas. The hepatocytes were clarified and swollen in the periportal areas.

Pruritus recurred at 19 months during chickenpox, though cholestyramine treatment had not been interrupted; jaundice reappeared 4 months later and the attack lasted 10 months. At $3 \frac{1}{2}$ years of age portal hypertension appeared. During the next year there were many attacks occurring with intercurrent infections, one of which was mumps. The child died at the age of $4 \frac{1}{2}$ from cirrhosis with jaundice and ascites.

Postmortem histological investigation showed distinct annular fibrosis with portal spaces all hypertrophic. However, no regeneration nodules were seen. There were no ductular formations, but a few round cells were shown (Fig. 2). Intralobular fibrosis had greatly increased and had become almost dissecting.

Case 4. A boy was born on 23 August 1969, weighing $2 \cdot 8 \mathrm{~kg}$. Jaundice and partial acholic stools were noticed at 4 months during an infection. The parents are unrelated. He is the youngest in a family of 11 children. The second (a boy), sixth (a girl), and seventh (a boy) children died from cholestatic cirrhosis at the ages of 8 years, 17 months, and 5 years, respectively; all 3 children developed jaundice between the ages of 6 and 9 months, pruritus following about 2 months later. The other children are healthy.

He was taken to hospital at the age of 6 months measuring $61 \mathrm{~cm}(-2 \mathrm{SD})$ and weighing $4.9 \mathrm{~kg}(-3$ SD). Jaundice was moderate, urine dark-coloured, stools normal; liver and spleen were enlarged. Laboratory tests showed moderate bilirubin retention, increase in alkaline phosphatase, and abnormal retention of bromsulphalein (Table I). At laparotomy the liver was large and firm. The extrahepatic bile ducts were normal. Peroperative cholangiography showed a normal and permeable bile duct. Histological examination of the liver biopsy showed normal portal triads without signs of fibrosis or inflammation and no ductular formation. Hepatocytes were little modified, but clearer in the areas of maximum biliary retention (Fig. 3).

Prednisone $(1.5 \mathrm{mg} / \mathrm{kg}$ per day) had no effect. Pruritus appeared at 8 months, and at 10 months the 


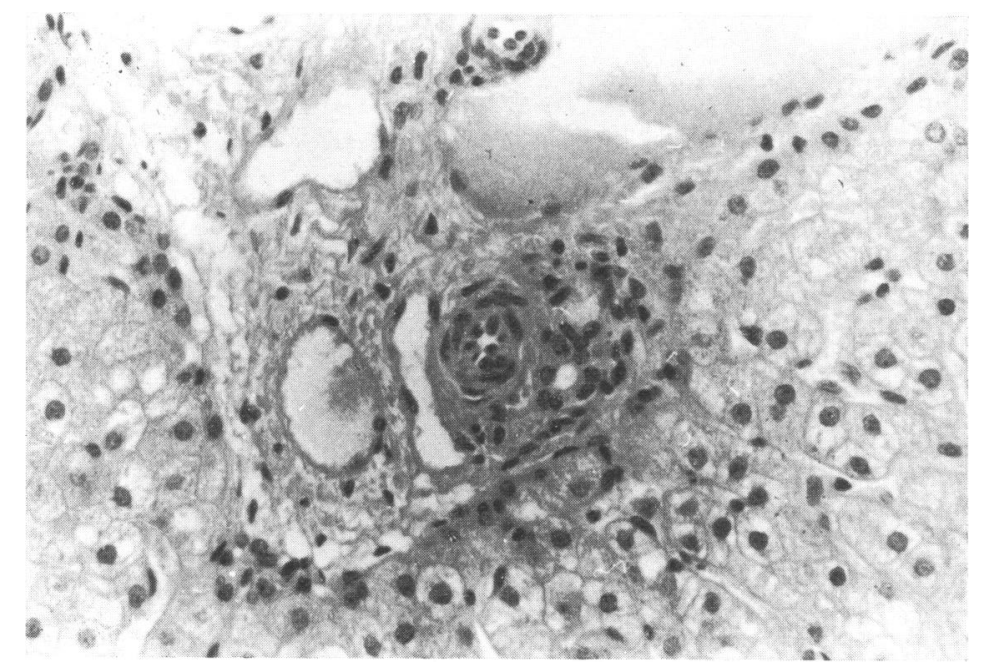

Fig. 3.-Case 4. Liver biopsy. Normal portal space. (Haematein eosin. $\quad \times 315$.

child measured $63 \mathrm{~cm}(-4 \mathrm{SD})$ and weighed only $5 \cdot 3 \mathrm{~kg}$ ( $-4 \mathrm{SD})$. Cholestasis persisted and cholestyramine ( 8 g/day) was prescribed. This treatment having also failed, the dose was doubled at the age of 16 months and the attack ceased 3 months later, though the liver remained large. Histological investigation by needle biopsy showed some portal hypertrophy that did not exist a year earlier. Interlobular bile ducts were still present but empty. At 28 months cholestyramine treatment was interrupted, and 3 days later pruritus, and later jaundice, reappeared; abnormal bromsulphalein retention was $52 \%$ at 15 minutes and $32 \%$ at 45 minutes. The attack lasted 5 months followed by incomplete remission, leaving an enlarged and hard liver.

Case 5. A girl was born on 24 January 1962. Jaundice began on the 8th day of life with acholic stools; histological examination of the liver showed the appearance of hepatitis with giant cells. Numerous attacks of cholestasis and pruritus, one after the other, took place until the age of $6 \frac{1}{2}$ years, when she was taken to hospital. The parents are unrelated. One brother died at 23 months with a large liver and jaundice; another brother died at 19 months with a large liver and with cholestatic jaundice which he had with varying intensity since the age of 8 days. A sister, age 11 years, is in good health. On admission the child measured $101 \mathrm{~cm}(-3$ $\mathrm{SD})$ and weighed $19 \mathrm{~kg}$ ( $-1 \mathrm{SD})$. The liver was large and hard; the spleen was also enlarged. Laboratory tests showed bilirubin retention, increased alkaline phosphatase, and abnormal retention of bromsulphalein (Table I). Laparotomy showed a large nodular liver; the gallbladder was tense and contained stones. Peroperative cholangiography showed good duodenal passages. Cholecystostomy was performed. Histological examination of liver biopsy specimen showed nodular cirrhosis with moderate inflammation. Inter- lobular bile ducts were present but empty. There were few ductular formations. Hepatocytes were light, large, and sometimes polynucleated (Fig. 4).

The child died 3 weeks later from hepatocellular insufficiency.

\section{Discussion}

The clinical picture in these 5 children was identical to that of 16 published cases (Clayton et al., 1965, 1969; Gray and Saunders, 1966; Hirooka and Ono, 1968; Linarelli et al., 1972; Schubert, 1965; Williams et al., 1972).

The cholestatic syndrome was incomplete. Jaundice was of varying intensity, accompanied by dark-coloured urine and partially acholic stools. Pruritus was generally severe; hepatomegaly was persistent. In all cases bilirubinaemia was increased (predominantly conjugated). Injected bromsulphalein was abnormally retained. In contrast, the total cholesterol and total lipids of the serum remained normal, even when cholestasis lasted several months. An exception was Case 2 of Williams et al. (1972) with significant lipid retention accompanied by cutaneous xanthoma, and also the case of Linarelli et al. (1972) where moderate cholesterolipid retention was noted. Alkaline phosphatase was moderately increased. Biliary acids in the serum were not measured in our cases.

In each case prolongation of cholestasis led to laparotomy to ascertain the permeability of the extrahepatic bile ducts. In each of our cases, the liver was enlarged, greenish, regular, or already nodular (Case 5). These findings are identical to the other 10 published cases in which laparotomy 


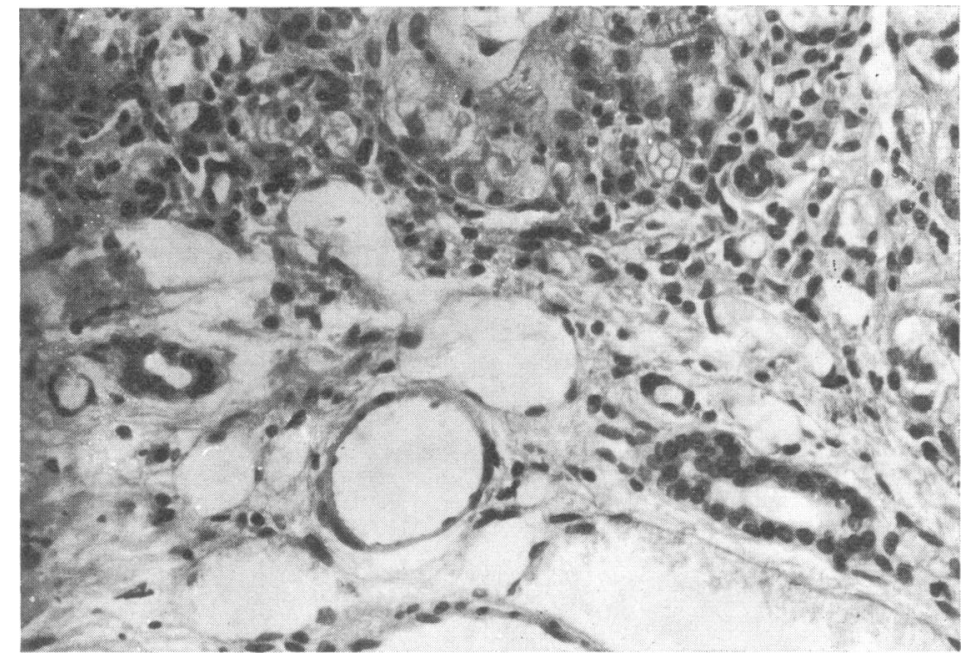

Fig. 4.-Case 5. Liver biopsy. Hypertrophic portal space. Elements of portal triad present. Presence of inflammatory cells. (Haematein eosin. $\times 315$.)

was performed (Clayton et al., 1969; Gray and Saunders, 1966; Hirooka and Ono, 1968; Williams et al., 1972.)

Histological examination of the liver in 4 cases showed portal fibrosis with a moderate number of round, inflammatory cells. In Case 3 there was also a marked intralobular fibrosis, almost dissecting, predominating in the centrolobular areas. In Cases 1 and 2 the portal fibrosis was accompanied by marked ductular formation. The histological picture in Case 4 was quite different since the portal space appeared entirely normal at the age of 7 months, whereas there was already an annular fibrosis in Case 3 at the age of one year. Development of the portal fibrosis was observed each time that repeated examinations were possible, as has been noted in published reports.

The disease follows a uniform course. Cholestasis progresses by attacks interrupted by remissions. In 3 of our cases the first attack occurred before the age of 6 months, in 2 cases between 6 and 10 months. When reviewing all known cases and the 7 sibs of our patients, the first symptoms appeared before the age of 6 months in 14 cases, between 6 and 12 months in 14 cases, and never appeared after 12 months. Each attack was related to an intercurrent infection, enabling us to foresee relapses in our cases; the parents of some of our patients asked for prophylaxis of common childhood infections, hoping to prevent clinical and biological relapse. Among the signs of cholestasis pruritus is often the first, followed sooner or later by the other signs of the disease. In our cases each attack lasted from a few days to 20 months. It is a fact that remission was never complete, since hepatomegaly was always observed between the attacks. Remissions became less and less distinct, and failure to thrive gradually became apparent, while the liver became hard and irregular, indicating that cirrhosis was gradually developing.

Of our 5 patients, 2 died: one (Case 3 ) at the age of $4 \frac{1}{2}$ without a true cirrhosis, the other (Case 5) at $6 \frac{1}{2}$ years with cirrhosis, the histology of which revealed regeneration nodules. In our 4 families, 6 sibs suffering from the disease died before the age of 5 , and the seventh at the age of 8 . Among the 28 cases known, 23 died of digestive bleeding due to portal hypertension or of decompensated cirrhosis, more rarely during superinfection. 15 of these deaths occurred before the age of 5,5 between 5 and 10 years, and 3 between 10 and 15 years of age. 3 of our children are still alive; one (Case 4) has early portal fibrosis, and the other two who are older (Cases 1 and 2) have more serious fibrosis.

Laparotomy in all our cases showed the absence of any obstacle in the principal bile duct; it is necessary in fact to be quite sure that the extrahepatic bile ducts are completely permeable in all cases of chronic cholestasis in children. Laparotomy also permitted major biopsy of each lobe in every case. This appeared necessary to us in order to rule out completely the possibility of atresia of the intrahepatic bile ducts which can cause incomplete and long-lasting cholestasis (Alagille et al., 1969); these 
bile ducts are easily recognized when there is no portal fibrosis, though they may be extremely difficult or even impossible to recognize when the clinical picture has evolved sufficiently and cirrhosis has already set in. Accurate identification of interlobular bile ducts was possible in all cases except Case 2. It is because these bile ducts could not be identified in the cases reported by Juberg $e t$ al. (1966)-cases that also had lipid retention-that we think it is wise, in contrast with other authors, not to include Juberg's work in our discussion.

The recurrent character of attacks of cholestasis should prompt discussion of other causes of chronic cholestasis: benign recurrent cholestasis (Summerskill and Walshe, 1959) and the type of familial cholestasis described by Aagenaes, Van der Hagen, and Refsum (1968) have a quite different course of development. It may be added that our patients were given no drug likely to cause cholestasis.

Treatment is of limited value. Cholecystostomy was carried out in 4 of our cases and appeared to be effective in Cases 1 and 2, but signs of cholestasis reappeared as soon as the catheter was removed. Drainage was ineffective in Case 3 and it was impossible to assess its role in Case 5; the same was true in the case of the sister of Case 3. However, internal biliary diversion later carried out in Case 1 proved ineffective. External biliary drainage appeared effective in one of the cases of Williams et al. (1972), but its effect was doubtful in one case reported by Gray and Saunders (1966) and nonexistent in one case of Clayton et al. (1969). In the latter case internal biliary derivation carried out later also proved ineffective.

Of our 5 patients, 4 were given cholestyramine. Only Case 4 appeared to benefit from this treatment. A similar favourable result was reported by Clayton et al. (1969) and Linarelli et al. (1972) in one each of their cases. In all other cases in which cholestyramine was administered for a sufficient length of time, there was no favourable effect. This disagreement between the results may perhaps be explained by insufficient dosage. It should be noticed, however, that of our 4 patients, the only one to benefit from the treatment was the youngest, at an age when portal fibrosis was still moderate.

The familial character of the disease is unquestionable in our 5 cases. The fact that 12 children in 4 families were affected suggests a recessive autosomal transmission; the consanguinity in the family of our Cases 1 and 2 argues in favour of this theory. These facts are in agreement with what is found in published reports, though 2 cases were isolated children; the report by Schubert (1965) concerned an adopted child and that of
Linarelli et al. (1972) had a family relationship with the families published by Clayton et al. (1969).

Until a biochemical definition of the disease is established, it will remain difficult to authenticate isolated cases in the absence of any familial context. Recent publications (Linarelli et al., 1972; Williams et al., 1972) note the abnormal presence of lithocholic acid in the serum of these children at the same time as a low level of excretion of normal biliary acids. We have made no precise study of the metabolism of biliary acids in our cases, and the possibility of cholestasis depending on different mechanisms from one family to another cannot be excluded. The relative frequency of associated anomalies in all cases might be an indirect argument in favour of an abnormality in the biliary acid metabolism. As shown in Table II, a certain number of facts can be

\section{TABLE II}

Principal biliary anomalies in severe familial intrahepatic cholestasis and age of discovery

\begin{tabular}{|c|c|}
\hline $\begin{array}{l}\text { Large gallbladder } \\
\text { Case } 3 \\
\text { Case } 5\end{array}$ & $\begin{array}{l}10 \mathrm{mth} \\
6 \frac{1}{2} \mathrm{yr}\end{array}$ \\
\hline $\begin{array}{l}\text { Gallstones } \\
\text { Case } 2 \\
\text { Case } 5\end{array}$ & $\begin{array}{l}4 \text { yr } \\
6 \frac{1}{2} \text { yr }\end{array}$ \\
\hline $\begin{array}{l}\text { Inspissated bile } \\
\text { Case } 1 \\
\text { Case } 3 \text { (Clayton et al., 1969) } \\
\text { Case } 1 \text { (Hirooka and Ono, 1968) } \\
\text { Case } 3 \text { (Williams et al., 1972) }\end{array}$ & $\begin{array}{l}4 \mathrm{yr} \\
9 \mathrm{mth} \\
2 \frac{1}{2} \mathrm{yr} \\
3 \frac{1}{2} \mathrm{yr}\end{array}$ \\
\hline $\begin{array}{l}\text { Bile plug } \\
\text { Case } 3\end{array}$ & $10 \mathrm{mth}$ \\
\hline $\begin{array}{l}\text { 'Chronic pancreatitis' appearance on laparotomy } \\
\text { Case } 2\end{array}$ & $4 \mathrm{yr}$ \\
\hline $\begin{array}{l}\text { Pancreatic calcifications on } \mathrm{x} \text {-rays } \\
\text { Case } 2 \\
\text { Case } 1 \\
\text { Case } 3 \text { (Williams et al., 1972) }\end{array}$ & $\begin{array}{l}7 \mathrm{yr} \\
7 \mathrm{yr} \\
10 \mathrm{yr}\end{array}$ \\
\hline
\end{tabular}

established in our cases and in those published reports. We thus noted the existence of a large gallbladder in 2 of our cases (Cases 3 and 5), and gallstones were also found in 2 cases, without the chemical composition of the calculi being studied. In several cases laparotomy revealed the existence of inspissated bile or a 'bile plug'. The appearance of 'chronic pancreatitis' in one of our cases (Case 2), and later proof of pancreatic calcifications in 3 cases are unusual. The toxic effects of lithocholic acid and its derivatives are beginning to be better recognized, at least in animals (Palmer, 1969). Cellular reaction of the ducts causing cirrhosis occurs in the rabbit. The rat can develop calculi in 
the principal bile duct (Palmer, 1969; Zaki et al., 1967). Biliary salts have also been involved in the aetiology of pancreatitis (Hansson et al., 1963). If the data concerning abnormal metabolism of biliary acids in these children were to be confirmed, the cases presented here could constitute an example in man of cholelithiasis and pancreatic pathology induced secondarily by this disorder of metabolism. The portal consequences of cirrhogenous cellular reaction of the ducts develop at the same time.

\section{REFERENCES}

Aagenaes, O., Van der Hagen, C. B., and Refsum, S. (1968). Hereditary recurrent intrahepatic cholestasis from birth. Archives of Disease in Childhood, 43, 646.

Alagille, D., Borde, J., Habib, E. C., and Thomassin, N. (1969). Tentatives chirurgicales au cours des atrésies des voies biliaires intrahépatiques avec voie biliaire extrahépatique perméable. Etude de quatorze observations chez l'enfant. Archives Françaises de Pédiatrie, 26, 51.

Clayton, R. J., Iber, F. L., Ruebner, B. H., and McKusick, V. A. (1965). Byler's disease: fatal familial intrahepatic cholestasis in an Amish kindred. Fournal of Pediatrics, 67, 1025.

Clayton, R. J., Iber, F. L., Ruebner, B. H., and McKusick, V. A. (1969). Byler's disease: fatal familial intrahepatic cholestasis in an Amish kindred. American fournal of Diseases of Children, 117, 112.

Gray, O. P., and Saunders, R. A. (1966). Familial intrahepatic cholestatic jaundice in infancy. Archives of Disease in Childhood, 41, 320.
Hansson, K., Lundh, G., Stenram, U., and Wallerstrom, A. (1963). Pancreatitis and free bile acids. Acta Chirurgica Scandinavica, 126, 338.

Hirooka, M., and Ono, T. (1968). A case of familial intrahepatic cholestasis. Tohoku fournal of Experimental Medicine, 94, 293.

Juberg, R. C., Holland-Moritz, R. M., Henley, K. S., and Gonzalez, C. F. (1966). Familial intrahepatic cholestasis with mental and growth retardation. Pediatrics, 38, 819.

Linarelli, L. G., Williams, C. N., and Phillips, M. J. (1972). Byler's disease: fatal intrahepatic cholestasis. Fournal of Pediatrics, 81, 484.

Palmer, R. H. (1969). Toxic effects of lithocholic acid and related 5 B-H steroids. In Bile Salt Metabolism, Vol. 1, p. 184 . Ed. by L. Schiff, J. B. Carey, and J. Dietschy. C. C. Thomas, Springfield, Illinois.

Schubert, W. K. (1965). Byler's disease : fatal familial intrahepatic cholestasis in an Amish kindred. (Discussion.) fournal of Pediatrics, 67, 1027.

Summerskill, W. H. J., and Walshe, J. M. (1959). Benign recurrent intrahepatic 'obstructive' jaundice. Lancet, 2, 686.

Williams, C. N., Kaye, R., Baker, L., Hurwitz, R., and Senior, J. R. (1972). Progressive familial cholestatic cirrhosis and bile acid metabolism. Fournal of Pediatrics, 81, 493.

Zaki, F. G., Carey, J. B., Jr., Hoffbauer, F. W., and Nwokolo, C. (1967). Biliary reaction and choledocholithiasis induced in the rat by lithocholic acid. Fournal of Laboratory and Clinical Medicine, 69, 737.

Correspondence to Dr. M. Odièvre, Hôpital Parrot, F 94270 Bicêtre, France.

\section{Addendum}

Since this paper was submitted, cholelithiasis was also discovered in Case 4 at the age of 4 years. 